\title{
Fabrication of a proton exchange membrane via blended sulfonimide functionalized polyamide
}

\author{
Yunfeng Zhang $\cdot$ Joycelyn Woo Yun Ting $\cdot$ Rupesh Rohan • \\ Weiwei Cai · Jing Li • Guodong Xu • Zhangxian Chen • \\ An Lin · Hansong Cheng
}

Received: 15 November 2013/Accepted: 15 January 2014/Published online: 31 January 2014

(C) The Author(s) 2014. This article is published with open access at Springerlink.com

\begin{abstract}
A novel linear non-fluorinated sulfonimide functionalized polyamide (SPA) polymer electrolyte was successfully synthesized via an aromatic sulfonimide monomer with superior thermal stability and superacidity. The aromatic sulfonimide remains stable below $220{ }^{\circ} \mathrm{C}$. To fabricate membranes with strong mechanical strength and dimensional stability, the polymer was blended with various quantities of PVdF. The PVdF/SPA blend membranes exhibit an excellent capacity of water uptake and high dimensional stability. However, their proton conductivity was found to be substantially lower than that of Nafion 211. Analysis on the SEM images of the PVdF/SPA blend membranes reveals that the low proton conductivity is primarily caused by the large pore structures $(>1 \mu \mathrm{m})$, which lead to breakdown of the continuous proton transport channels.
\end{abstract}

\section{Introduction}

Proton exchange membrane (PEM) fuel cell technology is considered as one of the key technologies for the incipient hydrogen economy [1, 2]. With an energy conversion

Y. Zhang · J. W. Y. Ting $\cdot$ R. Rohan - W. Cai · J. Li · G. Xu ·

Z. Chen $\cdot H$. Cheng $(\bowtie)$

Department of Chemistry, National University of Singapore, 3

Science Drive 3, Singapore 117543, Singapore

e-mail: chmch@nus.edu.sg

Y. Zhang $\cdot$ H. Cheng

Sustainable Energy Laboratory, China University of Geosciences

Wuhan, 388 Lumo RD, Wuhan 430074, China

A. Lin

College of Resource and Environmental Science of Wuhan

University, Wuhan 430072, China efficiency of 40-60\%, PEM fuel cells convert hydrogen into electricity directly with water as the only byproduct [3, 4]. In general, a PEM plays two important roles in a fuel cell by transporting hydrated protons and blocking the mass crossover between the anode and the cathode. While commercial PEMs based on perfluorosulphonic acid polymers, of which Nafion ${ }^{\circledR}$ is viewed as the "gold standard", often display high proton conductivity, excellent chemical stability, strong mechanical strength and flexibility, and potentially, long-term durability [5], they suffer from fuel permeation, electro-osmotic drag of water, reduced proton conductivity under relatively low humidity, environmentally unfriendliness, and high cost [6]. Furthermore, degradation of Nafion ${ }^{\circledR}$ membranes during fuel cell operation was also found to be a serious issue for stable fuel cell performance [7]. It has been confirmed that the membrane degradation is attributed to the chemical attack by hydroxyl free radicals produced from hydrogen peroxide, which is generated catalytically by metal impurities [8, 9]. The "weak" sites of Nafion ${ }^{\circledR}$, such as the polymer end groups $\left(-\mathrm{CF}_{2} \mathrm{COOH}\right)$ produced during membrane processing, are most accessible for the attack.

Chen et al. [9]. investigated Nafion ${ }^{\circledR}$ membrane degradation using $\mathrm{X}$-ray photoelectron spectroscopic technique. A decomposed product of cross-linking $\mathrm{S}-\mathrm{O}-\mathrm{S}$ was detected, indicating there is an additional "weak" site, $-\mathrm{SO}_{3} \mathrm{H}$, during the operation of PEMFC. In general, the sulfonic acid groups in sulfonated PEMs may also undergo degradation, which further affects the performances of fuel cells. To date, the majority of PEMs that have been reported depends on sulfonic acid to promote conductance of protons [10-13]. To avoid membrane degradation, new functional groups, such as phosphoric acid or sulfonimide group, to be utilized in the membrane materials as proton carriers, appear to be highly attractive alternatives. 
One of the functional groups, $\mathrm{CF}_{3} \mathrm{SO}_{2}-$, is known to be notoriously electron withdrawing, which enables the negative charge on the anionic species, $\mathrm{N}^{-}\left(\mathrm{SO}_{2} \mathrm{CF}_{3}\right)_{2}$ (TFSI), to be significantly delocalized. This unique property allows the TFSI salt to be widely utilized in lithium ion batteries [14-16] and ionic liquids [14-21]. Most recently, this functional group was also used in single ion conductive polymer electrolytes because the compounds yield high $\mathrm{Li}^{+}$ion transfer numbers arising from the high degree of charge delocalization and the anion immobilization with the anionic species being covalently bonded to the polymer backbones [22-28]. In addition to the superior electrochemical performance, these materials also display excellent thermal and chemical stabilities. Moreover, extensive efforts have been devoted to the development of sulfonamide-based polymer membranes for potential replacement of Nafion as PEMs because of their strong gas-phase superacidity, excellent thermal stability, capability to promote oxygen reduction kinetics at cathode, and weak adsorption on platinum catalyst [29-38]. Summer and co-workers [34] developed a class of polymers with a similar structure of Nafion but the sulfonic acid group is replaced by a sulfonimide group. This sulfonimide substituted membrane exhibits proton conductivity two-fold higher than that of Nafion 117. It also displays higher water uptake (WU) than that of Nafion 117 facilitated by the internal pores and/or the channel structures enabled by the sulfonimide acid groups. Nevertheless, utilization of the trifluoromethane group in the sulfonimide functionalized PEMs may result in membrane degradation and higher material costs.

To overcome the shortcoming but at the same time retain the good proton conductivity of Nafion, we designed and synthesized a non-fluorinated sulfonimide based PEM with tunable structure and properties. A non-fluorinated sulfonimide precursor, 4,4'-dicarboxyldiphenylsulfonimide, was first synthesized. With high thermal stability up to $320^{\circ} \mathrm{C}$ and strong acidity, the compound can be used to fabricate linear, comb-like or network structured SPA polymer electrolytes by taking advantage of the two carboxyl acid linkers. In this paper, we report synthesis and characterizations of a linear aromatic SPA based polymer electrolyte with a rigid structure. In order to fabricate mechanically strong membranes, a polyvinylidene fluoride (PVdF) was employed as a binder. The main properties of the blend membranes, specifically, the mechanical strength, WU and swelling, ion exchange capacity (IEC) and proton conductivity, were investigated and compared with the corresponding values of Nafion 211. The blend membranes display a higher water retention rate since sulfonimides interact with water more strongly than sulfonic acid [34]. Moreover, they also show good thermal stability up to $220{ }^{\circ} \mathrm{C}$ and better swelling property. However, these membranes exhibit lower proton conductivity than that of Nafion 211 arising from the interrupted internal pores and channel structures due to the poor compatibility between the flexible structure of the aliphatic PVdF binder and the rigid structure of the aromatic SPA polymer, based on the SEM analysis. The result provides useful information on how to design performance-enhanced blend membranes with tunable macro/micro porous structures through selecting appropriate structurally compatible polymers.

\section{Experimental}

\section{Materials}

4,4'-Diaminodiphenylsulfone (DADS), $p$-toluenesulfonamide and $p$-toluenesulfonylchloride were purchased from Sigma Aldrich. Pyridines, triphenylphosphite (TPP), $\mathrm{KMnO}_{4}$ and dimethyl sulfoxide (DMSO) were used as received without further purification. DADS was dried at $100{ }^{\circ} \mathrm{C}$ for $24 \mathrm{~h}$, Pyridine was dried with $\mathrm{KOH}$ and distilled. $N$-methyl-2-pyrrolidone (NMP) was distilled from $\mathrm{P}_{2} \mathrm{O}_{5}$ and calcium chloride $\left(\mathrm{CaCl}_{2}\right)$ was dried under vacuum at $180{ }^{\circ} \mathrm{C}$ for $24 \mathrm{~h}$ before use.

Preparation design and development of organic and ionic liquids for gas storage

The synthetic procedure is shown in Scheme 1. The synthesis of the SPA includes two steps: (1) preparation of the 4,4'-dicarboxyldiphenylsulfonimide monomer and (2) polymerization of SPA.

Synthesis of 4,4'-dimethyldiphenylsulfonimide (MBSI)

A homogeneous solution was prepared by dissolving $p$-toluenesulfonamide (17.122 g, $100 \mathrm{mmol}$ ) and $\mathrm{NaOH} 4.225 \mathrm{~g}$, $105 \mathrm{mmol}$ ) into $150 \mathrm{ml}$ of deionized water at $90{ }^{\circ} \mathrm{C}$. Subsequently, $p$-toluenesulfonylchloride (19.074 g, $100 \mathrm{mmol})$ was slowly added into the solution within $2 \mathrm{~h}$, and the reaction was then kept at $90{ }^{\circ} \mathrm{C}$ for another $12 \mathrm{~h}$. After adjusting the $\mathrm{pH}$ of the mixture to 7 by using a diluted $\mathrm{HCl}$, the reaction was left overnight. A sufficient amount of $\mathrm{HCl}$ was added to adjust the $\mathrm{pH}$ of the solution to 1 , yielding a white precipitate. The product was collected via filtration and then dried under vacuum overnight at $120{ }^{\circ} \mathrm{C}$. The final product $(20.665 \mathrm{~g})$ was obtained upon recrystallization from the deionized water. The yield was $63.5 \%$.

Synthesis of 4,4'-dicarboxyldiphenylsulfonimide monomer (CBSI)

A 4,4'-dicarboxyldiphenylsulfonimide monomer was obtained by oxidizing the methyl group of MBSI into 


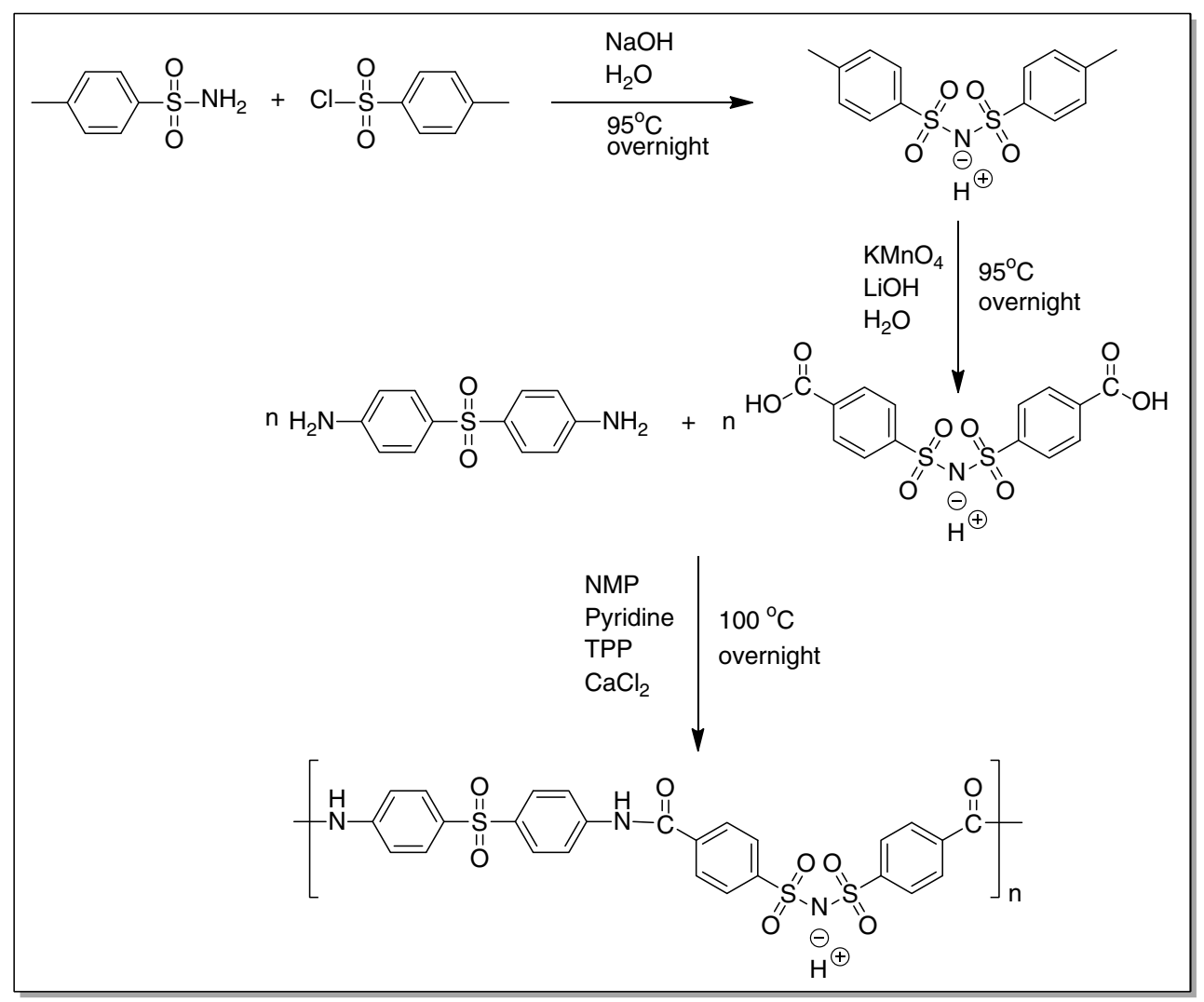

Scheme 1 Synthetic procedure of aromatic polyamide-sulfonimide, SPA

carboxyl group. 4,4'-Dimethyldiphenylsulfonimide (20.665 g, $63.51 \mathrm{mmol})$ and $\mathrm{LiOH} \cdot \mathrm{H}_{2} \mathrm{O}(2.690 \mathrm{~g}, 63.51 \mathrm{mmol})$ were then dissolved completely into deionized water $(300 \mathrm{~mL})$ at $95^{\circ} \mathrm{C} . \mathrm{KMnO}_{4}(20.068 \mathrm{~g}, 127.0 \mathrm{mmol})$ was slowly added into the solution within $2 \mathrm{~h}$. Subsequently, the reaction mixture was stirred at $95{ }^{\circ} \mathrm{C}$ overnight. Upon removal of $\mathrm{MnO}_{2}$ and the unreacted $\mathrm{KMnO}_{4}$ by filtration, the filtrate was acidified with concentrated $\mathrm{HCl}$. The final desired product was collected via acidification at last 5 times with a yield of $76.1 \%$.

Synthesis of sulfonimides functionalized polyamide based polymer electrolyte (SPA)

SPA was synthesized and purified based on the procedure described by Yamazaki et al. [39]. A mixture of CBSI (3.855 g, $10 \mathrm{mmol})$, DADS $(2.480 \mathrm{~g}, 10 \mathrm{mmol}), \mathrm{CaCl}_{2}$ $(2.80 \mathrm{~g}, 25.5 \mathrm{mmol})$, TPP $(5.2 \mathrm{ml})$ was added into a mixed solvent of NMP $(20 \mathrm{ml})$ and pyridine $(15 \mathrm{ml})$ and the reaction was kept at $100{ }^{\circ} \mathrm{C}$ for $12 \mathrm{~h}$ with stirring under argon atmosphere. After the reaction was completed, the mixture was cooled to $70{ }^{\circ} \mathrm{C}$ and then poured into $200 \mathrm{ml}$ cold methanol. A white precipitate was obtained by filtration and the pure product was collected upon continuous washing with methanol and deionized water. The product was finally dried at $140{ }^{\circ} \mathrm{C}$ under a reduced pressure for $6 \mathrm{~h}$. The molecular weight of the compound was evaluated using gel permeation chromatography with DMF as the eluent. The weight-average molecular weight $(\mathrm{Mw})$ of the SPA was $34,800 \mathrm{~g} / \mathrm{mol}$ and the polydispersity index was 3.67, suggesting that the SPA polymer was successfully synthesized.

Preparation of PVdF/SPA blend membranes

A series of PVdF/SPA blend membranes were prepared via a solution cast technique using DMSO as a solvent. The $8 \mathrm{wt} \%$ of the SPA solution and $8 \mathrm{wt} \%$ of the PVdF solution in DMSO were first prepared. The well mixed solution was then casted onto glass plates and dried at $80{ }^{\circ} \mathrm{C}$. The dried membranes were removed from the glass plates and further dried at $140{ }^{\circ} \mathrm{C}$ under vacuum for $24 \mathrm{~h}$. The prepared blend membranes were activated by soaking in $0.5 \mathrm{M} \mathrm{H}_{2} \mathrm{SO}_{4}$ at room temperature for $12 \mathrm{~h}$, and subsequently washed with ultrapure water repeatedly until the $\mathrm{pH}$ values of the wash solutions became 7 . The average thicknesses of the membranes measured were $50.96 \pm 4.75 \mu \mathrm{m}$ in a dry state. 
Characterization

\section{Thermal analysis}

Thermal analysis of the PVdF/SPA blend membranes was done via thermo gravimetric analysis (TGA), using SDT TA Instruments 2960 Simultaneous DTA-TGA, at $10.00^{\circ} \mathrm{C} / \mathrm{min}$ ramp up to $800{ }^{\circ} \mathrm{C}$, under nitrogen atmosphere. Samples were dried in a vacuum oven at $140{ }^{\circ} \mathrm{C}$ for $6 \mathrm{~h}$ before test.

\section{Scanning electron microscopy}

Surface morphologies of the PVdF/SPA blend membranes were investigated using JEOL JSM-6701F field emission scanning electron microscopy. Test specimens were sputter-coated with platinum before imaging.

\section{Tensile strength}

The tensile strength and elongation at break of the PVdF/ SPA blend membranes were measured according to ASTM D882, REF ASTM using an Instron Universal Materials Testing System (model 5544) with a $10 \mathrm{~N}$ load cell at $25{ }^{\circ} \mathrm{C}$ with constant relative humidity of $50 \%$. Rectangular-shaped samples were cut from the films (10 mm wide with a gauge length of $20 \mathrm{~mm}$ ). The thickness of the samples was measured with a digital micrometer with a precision of $1 \mu \mathrm{m}$ and sensitivity set at $40 \%$.

\section{Water uptake and swelling}

WU and dimensional swelling of the PVdF/SPA blend membranes were measured according to the following steps. The sorption process of water was firstly monitored at an interval of $2 \mathrm{~h}$ for $12 \mathrm{~h}$. Since no change was observed after $6 \mathrm{~h}$ for most of the membranes, a standard time of $12 \mathrm{~h}$ was set to measure the swelling index in the present work. For WU measurement, the membranes were first immersed in ultrapure water for $12 \mathrm{~h}$ at room temperature and weighted immediately upon removal of the surface water using a clean tissue paper $\left(W_{\text {wet }}\right)$. The membranes were then dried at $120{ }^{\circ} \mathrm{C}$ under vacuum for $6 \mathrm{~h}$ and weighted immediately $\left(W_{\text {dry }}\right)$. The WU was calculated according to the following equation:

$\mathrm{WU}(\%)=\frac{W_{\text {wet }}-W_{\text {dry }}}{W_{\text {dry }}} \times 100$

The measurement of blend membrane dimensional swelling was done in a similar way to that of WU. A strip with the predetermined dimensions $\left(4 \times 1 \mathrm{~cm}^{2}\right)$ of membrane was prepared first and then equilibrated in the deionized water for $12 \mathrm{~h}$ to obtain the wet length $\left(L_{\mathrm{wet}}\right)$. The wet membrane was then dried at $120{ }^{\circ} \mathrm{C}$ in vacuum for
$6 \mathrm{~h}$ to yield the dry length $\left(L_{\mathrm{dry}}\right)$. The water swelling was calculated as:

$\mathrm{WS}(\%)=\frac{L_{\mathrm{wet}}-L_{\mathrm{dry}}}{L_{\mathrm{dry}}} \times 100$.

Ion exchange capacity

The PVdF/SPA membranes (0.1-0.2 g) were first immersed in $100 \mathrm{ml}$ of $0.5 \mathrm{M} \mathrm{NaCl}$ for at least $48 \mathrm{~h}$ so as to fully convert $\mathrm{H}^{+}$of the sulfonimide to $\mathrm{Na}^{+}$. The contents of $\mathrm{H}^{+}$were measured by titration with $0.01 \mathrm{M} \mathrm{NaOH}$ using phenolphthalein as the indicator. The operation was repeated at least three times to acquire the exact data. IEC was calculated using Eq. (3):

$\mathrm{IEC}=\frac{V_{\mathrm{NaOH}}(\mathrm{L}) \times[\mathrm{NaOH}]\left(\frac{\mathrm{mol}}{\mathrm{L}}\right)}{W(\mathrm{~g})}(\mathrm{mol} / \mathrm{g})$

where $V_{\mathrm{NaOH}}$ is the volume of $\mathrm{NaOH},[\mathrm{NaOH}]$ is the concentration of $\mathrm{NaOH}$ and $\mathrm{W}$ is the weight of PVDF/SPA membrane.

\section{Proton conductivity}

Proton conductivity was determined in a sandwiched SSI PEMISS cell by electrochemical impedance spectroscopy (EIS) using a potentiostat-galvanostat AUTOLAB model PGSTAT12/30/302 over a frequency range of $10-4 \mathrm{MHz}$ with the oscillating voltage of $5 \mathrm{mV}$. The blend membranes were pretreated in the $0.1 \mathrm{M} \mathrm{H}_{2} \mathrm{SO}_{4}$ solution for $24 \mathrm{~h}$ and then in the ultrapure water for $24 \mathrm{~h}$. Proton conductivity was calculated from the impedance data using the equation:

$\sigma=\frac{l}{R \cdot A}$

where $\sigma$ is the proton conductivity $\left(\mathrm{S} \mathrm{cm}^{-1}\right), 1$ is the membrane thickness $(\mathrm{cm}), R$ is the membrane resistance $(\Omega)$ associated with the ionic conductivity of the membranes, which was determined from the high frequency intercept of the impedance with the real axis, and $A$ is the membrane surface area $\left(\mathrm{cm}^{2}\right)$.

\section{Results and discussion}

\section{FTIR spectroscopies}

Figure 1 shows the overlaid FTIR spectra of the pristine SPA, pristine PVdF and PVdF/SPA blend membranes. Several bands are present during the formation of the SPA. The intensity of the characteristic bands of amide $\mathrm{C}=\mathrm{O}$ stretching $\left(1662 \mathrm{~cm}^{-1}\right)$ and $\mathrm{C}=\mathrm{C}$ aromatic stretching (1591, 1527 and $1494 \mathrm{~cm}^{-1}$ ) decreases as the SPA content in the membranes decreases. Moreover, the $\beta$-phase PVdF 


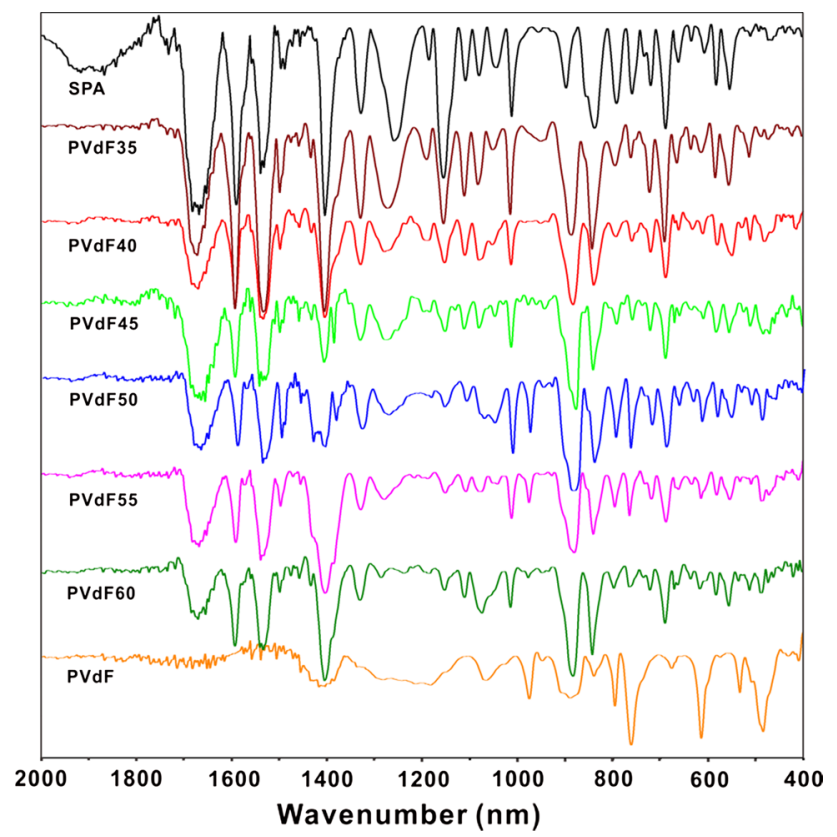

Fig. 1 FTIR spectra of PVdF/SPA blend membranes and pristine SPA and PVdF

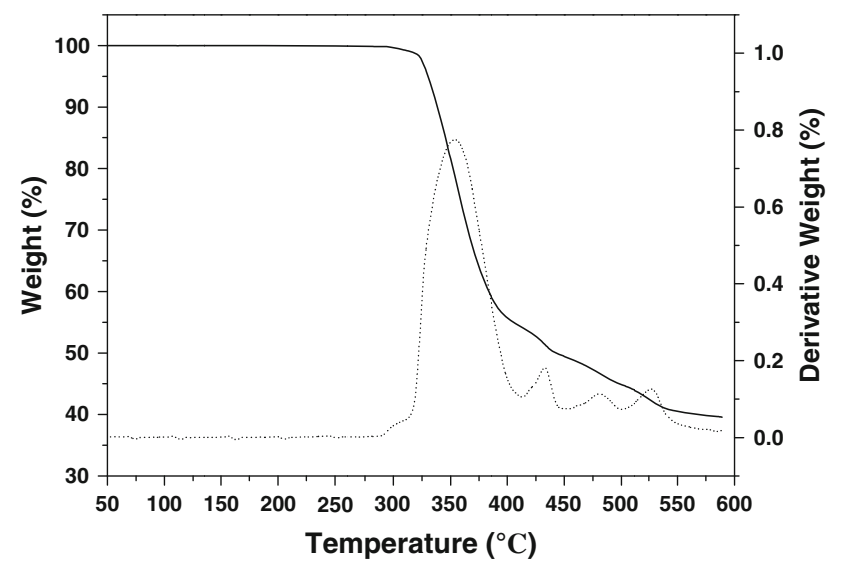

Fig. 2 Thermal stability of 4,4'-dicarboxyldiphenylsulfonimide homopolymer peak identified at $480 \mathrm{~cm}^{-1}$ [40] increases slightly with the increase of the PVdF content.

Thermal and mechanical strength

TGA was carried out to examine the thermal stability of the synthesized materials under flowing nitrogen atmosphere. Figure 2 shows the TGA spectrum of the 4,4'-dicarboxyldiphenylsulfonimide monomer, which displays good thermal stability up to $320{ }^{\circ} \mathrm{C}$. Shown in Fig. 3 are the TGA curves and DTG curves of the pristine SPA, the pristine PVdF and PVdF/SPA blend membranes. The small amount of weight loss of the pristine SPA and PVdF/SPA before $100{ }^{\circ} \mathrm{C}$ is attributed to desorption of water molecules. However, no weight loss is observed for the pristine PVdF before $100{ }^{\circ} \mathrm{C}$, suggesting that the SPA polymers possess promising hydrophilicity that may enhance the WU capacity. It is also evident from Fig. 3 that the SPA polymers first undergo a slight weight loss at $220{ }^{\circ} \mathrm{C}$, indicating that these blend membranes exceed the thermal stability requirement for the operation temperatures of PEM fuel cells. Moreover, the weight loss of

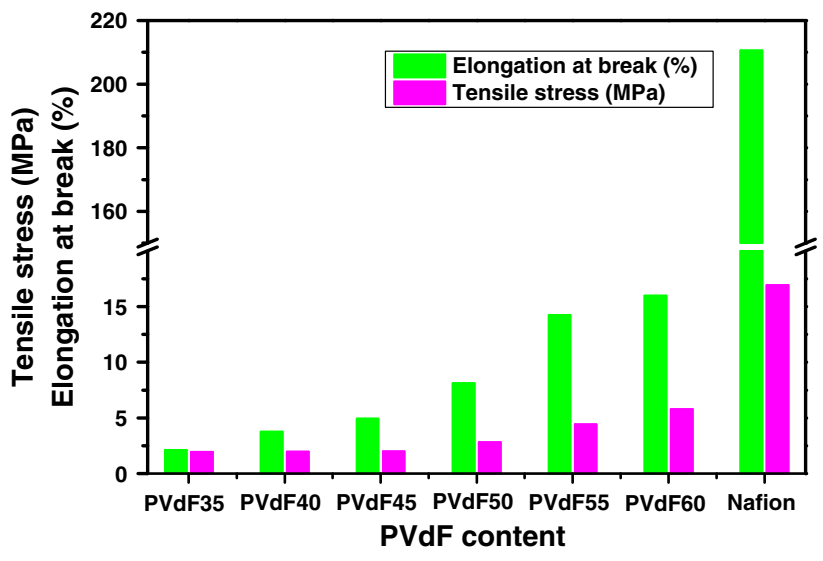

Fig. 4 Tensile strength and elongation break of PVDF/SPA blend membranes and Nafion 211
Fig. 3 Thermal stabilities (a) and dTG curves (b) of PVdF/SPA blend membranes and pristine SPA and PVdF
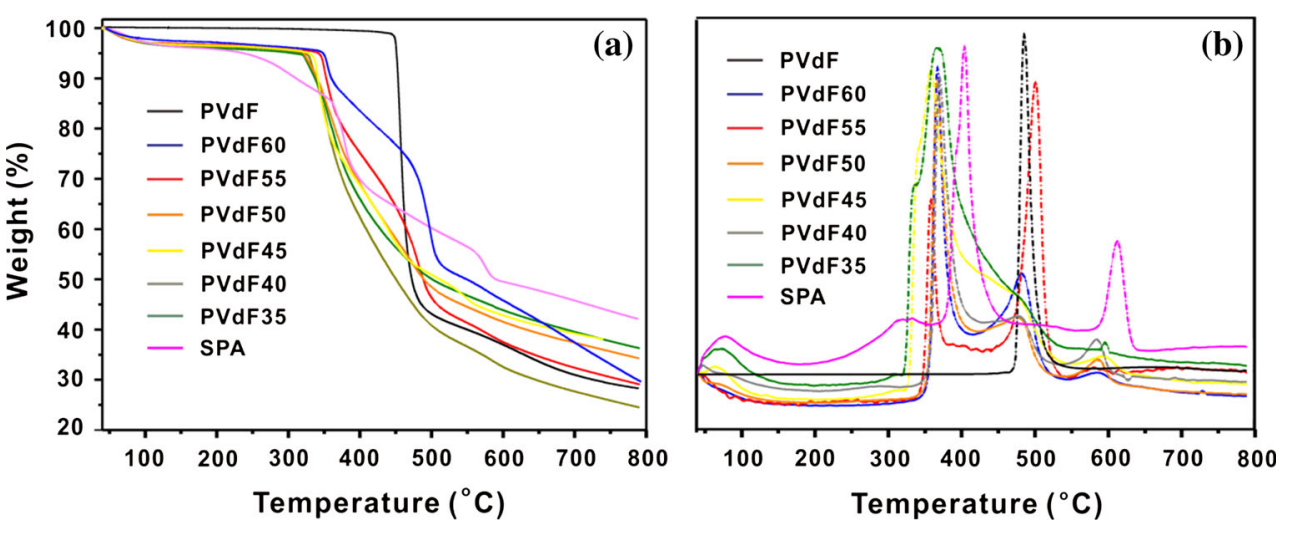


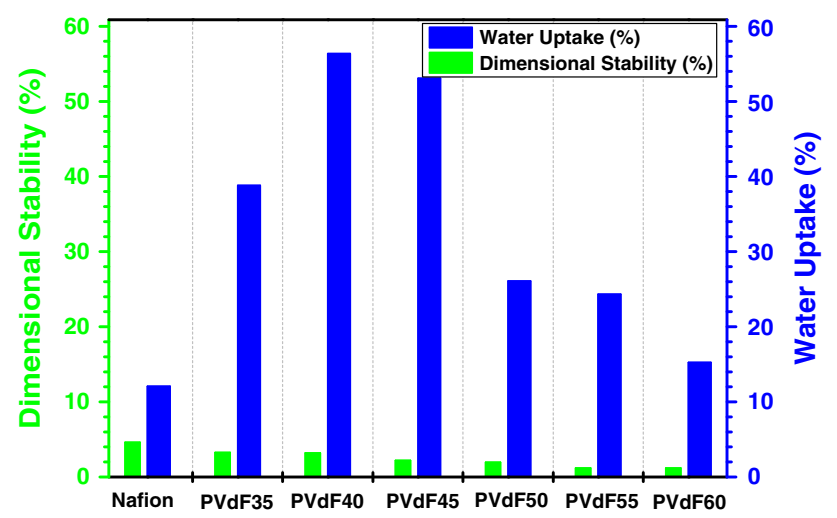

Fig. 5 Dimensional stability (green) and water uptake ability (blue) of the PVdF/SPA blend membranes (Color figure online)

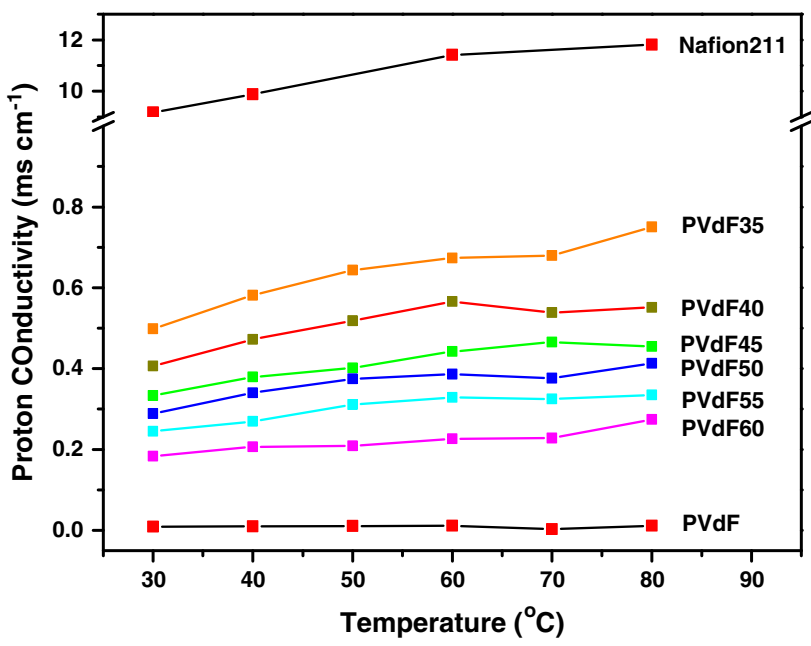

Fig. 6 Proton conductivity of $\mathrm{PVdF} / \mathrm{SPAblend}$ membranes as a function of temperature the initial decomposition increases as the SPA polymer content in the PVdF/SPA blended membranes increases.

The mechanical properties of the PVdF/SPA blend membranes and Nafion 211 were also measured in their dry state in an ambient environment and compared in Fig. 4. The tensile strength increases with the PVdF content in the blend membranes. However, the tensile strengths of all the PVdF/SPA membranes are significantly weaker than that of the Nafion 211 membrane. The elongation at break increases with the PVdF content. However, it is significantly lower than that of Nafion 211, which has extremely high elongation at break of $211 \%$.

Water uptake and water swelling

Sufficient WU is one of the essential requirements for a potential PEM since water is the medium for proton conduction in the membrane. However, excessive water retention may give rise to a swelling problem and thereby result in dimensional instability of the membrane. The dimensional instability during hydration/dehydration cycle for PEMFC operation could lead to interfacial delamination between the electrode and the PEM and thus significantly affect cell performance [41]. Figure 5 shows the WU and the dimensional swelling ratio of the PVdF/SPA blend membranes in terms of $\mathrm{PVdF}$ content ranging from 35 to $60 \mathrm{wt} \%$. The WU in the membranes increases with the SPA content when the PVdF content is higher than $40 \mathrm{wt} \%$. In particular, PVdF35 displays slightly lower WU than PVdF40 even though the former has a higher content of sulfonimide groups. It turns out that the lower WU is due to the state of water presence in the blend membranes,
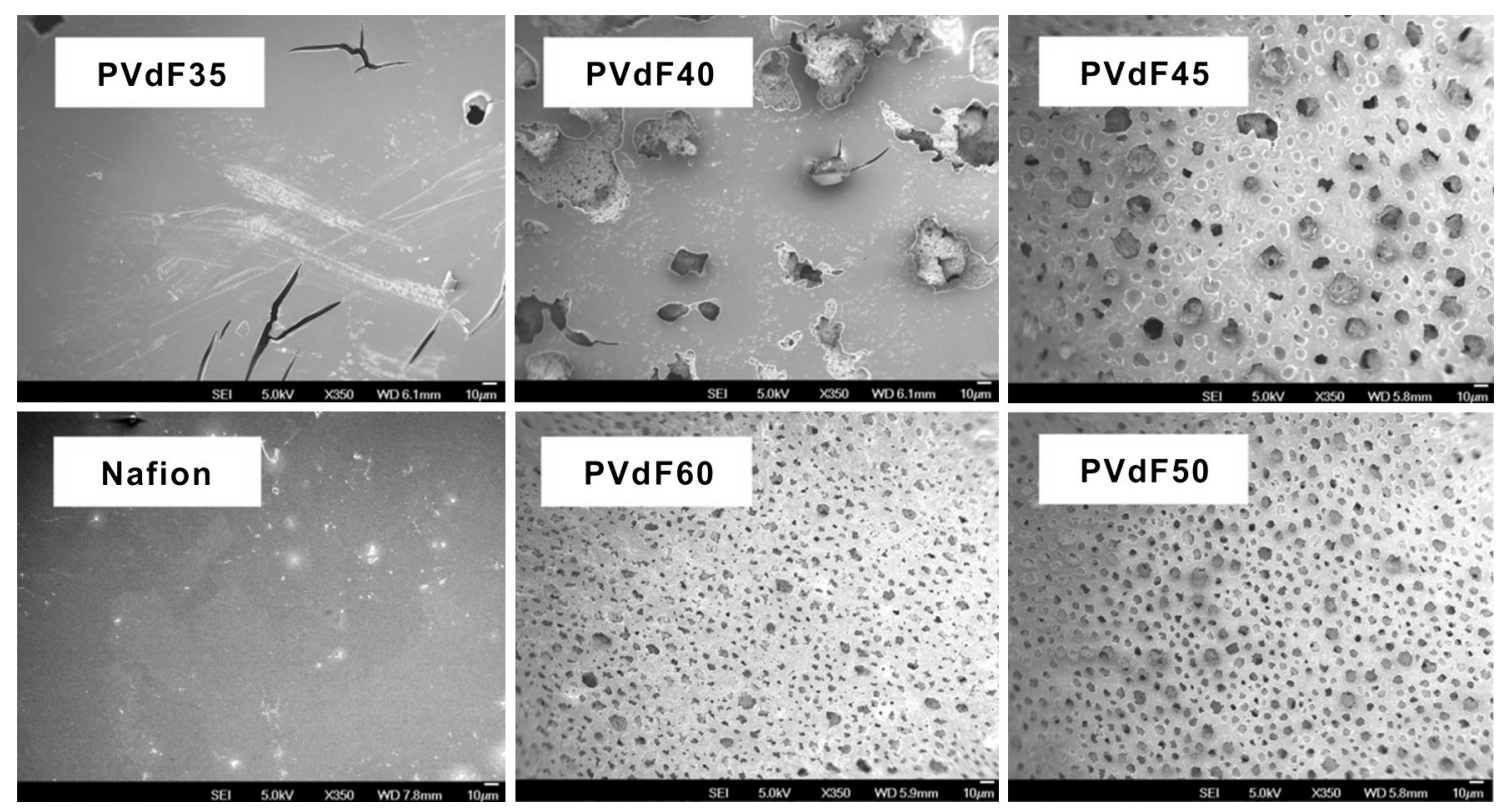

Fig. 7 SEM images of series of PVdF/SPA blend membranes and Nafion 211 
which is closely related to the membrane morphology, as will be explained via the analysis on the SEM images later.

Proton conductivity

The proton conductivity of the PVdF/SPA blend membranes is shown in Fig. 6 as a function of temperature. Membranes with higher SPA contents exhibit higher proton conductivity due to the higher concentration of protons arising from the acidic sulfonimide groups. Furthermore, the proton conductivity increases with temperature due to the higher proton mobility, as expected. Unfortunately, the proton conductivity of the blend membranes is substantially lower than that of Nafion 211, indicating that water retention capacity does not necessarily correlate with proton conductivity since WU in Nafion 211 is lower than in the PVdF/SPA membranes. Pourcelly et al. [42]. reported that fully hydrated membranes contain three types of water:

(1) non-freezing water bound to the sulfonic acid groups,

(2) freezable water weakly bound to the ionic groups and the polymer matrix and (3) free water not intimately bound

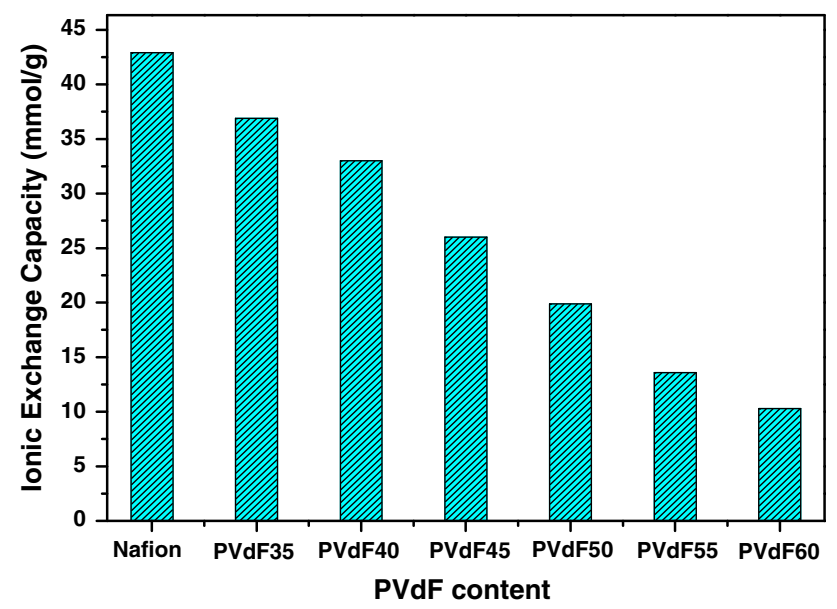

Fig. 8 Ion exchange capacity of PVdF/SPA blend membranes of different PVDF content to a polymer chain behaving like bulk water. From the SEM images shown in Fig. 7, the PVdF/SPA blend membranes exhibit extremely porous and coarse surface morphologies with a pore size of around $10 \mu \mathrm{m}$ while the Nafion membranes usually display smooth surfaces. This morphologic difference might explain the lower conductivity and the higher water retention rate of the PVdF/SPA membranes compared with the properties of Nafion. The high WU arises mainly from the free water molecules in the pores. These molecules do not intimately bound to the polymer chains and behave like bulk water. Furthermore, the large pore size $(>1 \mu \mathrm{m})$ may cut off the continuous proton conducting channels. As a consequence, the proton conductivity of the PVdF/SPA membranes becomes substantially lower than that of Nafion.

The importance of membrane quality on proton conductivity is further underscored from the comparison between the SEM images and the measured proton conductivity. It is evident from Fig. 7 that the morphologies of the blend membranes are largely affected by the PVdF content. The smoothness of the membranes, which indicating formation of continuous conducting channels essential for enhancement of proton conductivity, increases with the decrement of PVdF content in the blends. PVdF35 displays the smoothest surface and the highest proton conductivity, even with the lowest WU among all the blend membranes. The increase of the formation of pores with the increment of PVdF content in the blend membranes may be attributed to the poor compatibility between PVdF and SPA. Despite the presence of polar groups in the blend, which enhances the membrane strength through dipole-dipole interactions, the structural rigidness of SPA may be the root cause for the poor compatibility, which becomes increasingly pronounced as the $\mathrm{PVdF}$ proportion increases in the blend.

\section{Ion exchange capacity}

IEC is another important parameter for PEMs. A high IEC is required to insure high proton conductivity. Figure 8

Table 1 Tabulated data of properties of PVdF/SPA blend membranes and Nafion 211

\begin{tabular}{|c|c|c|c|c|c|c|}
\hline & $\begin{array}{l}\text { Water } \\
\text { uptake }(\%)\end{array}$ & $\begin{array}{l}\text { Water } \\
\text { swelling (\%) }\end{array}$ & IEC & $\begin{array}{l}\text { Proton conductivity } \\
\left(\times 10^{-3} \mathrm{~S} \mathrm{~cm}^{-1}\right)^{\mathrm{a}}\end{array}$ & $\begin{array}{l}\text { Tensile } \\
\text { stress (MPa) }\end{array}$ & $\begin{array}{l}\text { Elongation } \\
\text { at break }(\%)\end{array}$ \\
\hline PVdF35 & 38.8 & 3.28 & 36.9 & 0.751 & 1.95 & 2.12 \\
\hline PVdF40 & 56.4 & 3.20 & 33.0 & 0.552 & 1.98 & 3.77 \\
\hline PVdF45 & 53.1 & 2.23 & 26.0 & 0.455 & 1.99 & 4.94 \\
\hline PVdF50 & 26.1 & 1.96 & 19.9 & 0.413 & 2.83 & 8.12 \\
\hline PVdF55 & 24.4 & 1.19 & 13.6 & 0.335 & 4.42 & 14.3 \\
\hline PVdF60 & 15.2 & 1.20 & 10.3 & 0.274 & 5.78 & 16.0 \\
\hline Nafion 211 & 12.1 & 4.62 & 42.9 & 11.81 & 16.9 & 211 \\
\hline
\end{tabular}

${ }^{a}$ Proton conductivity was measured at $80{ }^{\circ} \mathrm{C}$. The rest of the data all measured at ambient temperature 
illustrates the IEC values of the PVdF/SPA membranes. The IEC of the membranes increases as the PVdF content decreases. The IEC value of PVdF35 is $36.9 \mathrm{mmol} / \mathrm{g}$, very close to the value of $42.9 \mathrm{mmol} / \mathrm{g}$ of Nafion 211. A high IEC value of a membrane enhances water retention and proton conductivity but may also cause an extreme dimensional swelling problem. Therefore, an appropriate balance between IEC and dimensional swelling must be maintained (Table 1).

\section{Summary}

A sulfonimide based SPA polymer with an adjustable linear, comb-like or network structure, was designed and successfully synthesized. To enhance the mechanical strength and to improve dimensional stability of the polymer, PVdF was utilized as a binder for fabrication of blend membranes with various binders to polymer ratios. Subsequently, the performance of these membranes as potential PEM materials for applications in fuel cells was examined. All PVdF/SPA blend membranes exhibit higher WU and better dimensional stability than Nafion 211 . Unfortunately, they also display much lower proton conductivity than the Nafion membrane despite the higher WU. The SEM images suggest that the free water stored in the pores is primarily responsible for the high WU. The large porosity in the membrane breaks down the continuous proton conduction channels. To boost the conductivity of the SPA membranes to be competitive to that of Nafion, the quality of the polymer films must be significantly improved with higher density and better uniformity, which requires selecting more miscible binders with the SPA polymer and optimizing the preparation conditions of the polymer blends. In addition, doping with metal oxides into the polymer blends may also enhance the membrane performance, which is the subject of our future studies.

Acknowledgements The authors gratefully acknowledge support of a start-up grant from NUS, a POC grant from National Research Foundation of Singapore and the National Natural Science Foundation of China (No. 21233006).

Open Access This article is distributed under the terms of the Creative Commons Attribution License which permits any use, distribution, and reproduction in any medium, provided the original author(s) and the source are credited.

\section{References}

1. Smitha B, Sridhar S, Khan AA (2005) Solid polymer electrolyte membranes for fuel cell applications: a review. J Membr Sci 259:10-26
2. Alberti G, Casciola M, Massinelli L, Bauer B (2001) Polymeric proton conducting membranes for medium temperature fuel cells $\left(110-160{ }^{\circ} \mathrm{C}\right)$. J Membr Sci 185:73-81

3. Liu H, Logan BE (2004) Electricity generation using an aircathode single chamber microbial fuel cell in the presence and absence of a proton exchange membrane. Environ Sci Technol 38:4040-4046

4. Comparison of Fuel Cell Technologies, U.S. Department of Energy, Energy Efficiency and Fuel Cell Technologies Program February 2011, Accessed Aug 42011

5. Kreuer KD (2001) On the development of proton conducting polymer membranes for hydrogen and methanol fuel cells. J Membr Sci 185:29-39

6. Mauritz KA, Moore RB (2004) State of understanding of Nafion. Chem Rev 104:4535-4586

7. Collier A, Wang HJ, Yuan XZ, Zhang JJ, Wilkinson DP (2006) Degradation of polymer electrolyte membranes. Int $\mathrm{J}$ Hydrog Energy 31:1838-1854

8. Curtin DE, Lousenberg RD, Henry TJ, Tangeman PC, Tisack ME (2004) Advanced materials for improved PEMFC performance and life. J Power Sources 131:41-48

9. Chen C, Levitin G, Hess DW, Fuller TF (2007) XPS investigation of Nafion ${ }^{\circledR}$ membrane degradation. J Power Sources 169: 288-295

10. Chikashige Y, Chikyu Y, Miyatake K, Watanabe M (2005) Poly(arylene ether) ionomers containing sulfofluorenyl groups for fuel cell applications. Macromolecules 38:7121-7126

11. Annala M, Lipponen S, Kallio T, Seppala J (2012) Proton conductive reinforced poly(ethylene-co-styrene) membranes. J Appl Polym Sci 124:1511-1519

12. Erce S, Erdener H, Akay RG, Yucel H, Bac N, Eroglu I (2009) Effects of sulfonated polyether-etherketone (SPEEK) and composite membranes on the proton exchange membrane fuel cell (PEMFC) performance. Int J Hydrog Energy 34:4645-4652

13. Shang XY, Fang SM, Meng YZ (2007) Synthesis and characterization of poly(arylene ether ketone) with sulfonated fluorene pendants for proton exchange membrane. J Membr Sci 297:90-97

14. Tominaga Y, Ohno H (1998) Improved ionic conductivity of $\mathrm{PEO} /$ sulfonamide lithium salt hybrid by the addition of LiTFSI. Chem Lett 27:955-956

15. Bouchet R, Lascaud S, Rosso M (2003) An EIS study of the anode Li/PEO-LiTFSI of a Li polymer battery. J Electrochem Soc 150:A1385-A1389

16. Zhao Y, Tao R, Fujinami T (2006) Enhancement of ionic conductivity of PEO-LiTFSI electrolyte upon incorporation of plasticizing lithium borate. Electrochim Acta 51:6451-6455

17. Martinelli A, Matic A, Jacobsson P, Borjesson L, Fernicola A, Scrosati B (2009) Phase behavior and ionic conductivity in lithium bis(trifluoromethanesulfonyl)imide-doped ionic liquids of the pyrrolidinium cation and bis(trifluoromethanesulfonyl)imide anion. J Phys Chem B 113:11247-11251

18. Best AS, Bhatt AI, Hollenkamp AF (2010) Ionic liquids with the bis(fluorosulfonyl) imide anion: electrochemical properties and applications in battery technology. J Electrochem Soc 157:A903A911

19. Fernicola A, Croce F, Scrosati B, Watanabe T, Ohno H (2007) LiTFSI-BEPyTFSI as an improved ionic liquid electrolyte for rechargeable lithium batteries. J Power Sources 174:342-348

20. Sun XG, Dai S (2010) Electrochemical investigations of ionic liquids with vinylene carbonate for applications in rechargeable lithium ion batteries. Electrochim Acta 55:4618-4626

21. Huang JH, Hollenkamp AF (2012) Thermal behavior of ionic liquids containing the FSI anion and the $\mathrm{Li}+$ cation. J Phys Chem C 114:21840-21847 
22. Meziane R, Bonnet J-P, Courty M, Djellab K, Armand M (2011) Single-ion polymer electrolytes based on a delocalized polyanion for lithium batteries. Electrochim Acta 57:14-19

23. Feng SW, Shi DY, Liu F, Zheng LP, Nie J, Feng WF, Huang XJ, Armand M, Zhou ZB (2013) Single lithium-ion conducting polymer electrolytes based on poly (4-styrenesulfonyl)(trifluoromethanesulfonyl)imide anions. Electrochim Acta 93:254-263

24. Herath MB, Creager SE, Rajagopal RV, Geiculescu OE, DesMarteau DD (2009) Ionic conduction in polyether-based lithium arylfluorosulfonimide ionic melt electrolytes. Electrochim Acta 54:5877-5883

25. Matsumoto K, Endo T (2011) Synthesis of networked polymers by copolymerization of monoepoxy-substituted lithium sulfonylimide and diepoxy-substituted poly(ethylene glycol), and their properties. J Polym Sci Pol Chem 49:1874-1880

26. Hofmann MA, Ambler CM, Maher AE, Chalkova E, Zhou XY, Lvov SN, Allcock HR (2002) Synthesis of polyphosphazenes with sulfonimide side groups. Macromolecules 35:6490-6493

27. Allcock HR, Welna DT, Maher AE (2006) Single ion conductorspolyphosphazenes with sulfonimide functional groups. Solid State Ion 177:741-747

28. Bouchet R, Maria S, Meziane R, Aboulaich A, Lienafa L, Bonnet J-P, Phan TNT, Bertin D, Gigmes D, Devaux D, Denoyel R, Armand M (2013) Single-ion BAB triblock copolymers as highly efficient electrolytes for lithium-metal batteries. Nat Mater $12: 452-457$

29. Rahman MK, Aiba G, Susan MABH, Sasaya Y, Ota K-I, Watanabe M (2004) Synthesis, characterization, and copolymerization of a series of novel acid monomers based on sulfonimides for proton conducting membranes. Macromolecules 37:5572-5577

30. Rahman MK, Aiba G, Susan MABH, Watanabe M (2004) Proton exchange membranes based on sulfonimide for fuel cell applications. Electrochim Acta 50:633-638

31. Koppel IA, Taft RW, Anvia F, Zhu S-Z, Hu L-Q, Sung K-S, DesMarteau DD, Yagupolskii LM, Yagupolskii YL (1994) The gas-phase acidities of very strong neutral bronsted acids. J Am Chem Soc 116:3047-3057

32. Razaq M, Razaq A, Yeager E, Desmarteau DD, Singh S (1989) Perfluorosulfonimide as an additive in phosphoric-acid fuel-cell. J Electrochem Soc 136:385-390

33. Appleby AJ, Velev OA, Lehelloco JG, Parthasarthy A, Srinivasan S, Desmarteau DD, Gillette MS, Ghosh JK (1993) Polymeric perfluoro bis-sulfonimides as possible fuel-cell electrolytes. J Electrochem Soc 140:109-111

34. Sumner JJ, Creager SE, Ma JJ, DesMarteau DD (1998) Proton conductivity in Nafion (R) 117 and in a novel bis (perfluoroalkyl)sulfonyl imide ionomer membrane. J Electrochem Soc 145:107-110

35. Yasuda T, Okimura Y, Oishi A, Kokubo H, Watanabe M (2013) Alternating copolymer based on sulfonamide-substituted phenylmaleimide and vinyl monomers as polymer electrolyte membrane. J Polym Sci Pol Chem 51:2233-2242

36. Oishi A, Matsuoka H, Yasuda T, Watanabe M (2009) Novel styrene $/ N$-phenylmaleimide alternating copolymers with pendant sulfonimide acid groups for polymer electrolyte fuel cell applications. J Mater Chem 19:514-521

37. Cho CG, Kim YS, Yu X, Hill M, McGrath JE (2006) Synthesis and characterization of poly(arylene ether sulfone) copolymers with sulfonimide side groups for a proton-exchange membrane. J Polym Sci Pol Chem 44:6007-6014

38. Flach AM, Johnson FE, Cabasso I (2013) Synthesis and characterization of fluorinated polyionomers. Part I: polyperfluoro-sulfonylethoxy propylene vinyl ether sulfonimides containing aryl sulfonic acids. Poly Chem 4:3370-3383

39. Yamazaki N, Matsumoto M, Higashi F (1975) Studies on reactions of n-phosphonium salts of pyridines. 14. wholly aromatic polyamides by direct polycondensation reaction by using phosphites in presence of metal-salts. J Polym Sci Pol Chem 13:1373-1380

40. Jin-Woo Park Y-AS, Kim Il, Ha Chang-Sik (2004) Investigating the crystalline structure of poly(vinylidene fluoride) (PVDF) in PVDF/silica binary and PVDF/poly(methyl methacrylate)/silica ternary hybrid composites using FTIR and solid-state 19F MASNMR spectroscopy. Macromolecules 37:429-436

41. Jung H-Y, Park J-K (2007) Blend membranes based on sulfonated poly(ether ether ketone) and poly(vinylidene fluoride) for high performance direct methanol fuel cell. Electrochim Acta 52:7464-7468

42. Pourcelly G, Oikonomou A, Gavach C, Hurwitz HD (1990) Influence of the water content on the kinetics of counter-ion transport in perfluorosulphonic membranes. J Electroanal Chem Interfacial Electrochem 287:43-59 